\title{
Parental occupations of children with leukaemia in west Cumbria, north Humberside, and Gateshead
}

\author{
P A McKinney, F E Alexander, R A Cartwright, L Parker
}

\begin{abstract}
Objective-To determine whether parental occupations and chemical and other specific exposures are risk factors for childhood leukaemia.

Design-Case-control study. Information on parents was obtained by home interview.

Setting - Three areas in north England: Copeland and South Lakeland (west Cumbria); Kingston upon Hull, Beverley, East Yorkshire, and Holderness (north Humberside), and Gateshead.

Subjects - 109 children aged 0-14 born and diagnosed as having leukaemia or non-Hodgkin's lymphoma in study areas during 1974-88. Two controls matched for sex and date and district of birth were obtained for each child.
\end{abstract}

Main outcome measures-Occupations of parents and specific exposure of parents before the children's conception, during gestation, and after birth. Other adults living with the children were included in the postnatal analysis.

Results-Few risk factors were identified for mothers, although preconceptional association with the food industry was significantly increased in case mothers (odds ratio $2 \cdot 56 ; 95 \%$ confidence interval 1.32 to $5 \cdot 00$ ). Significant associations were found between childhood leukaemia and reported preconceptional exposure of fathers to wood dust $(2 \cdot 73$, 1.44 to 5.16$)$, radiation $(3.23,1.36$ to 7.72$)$, and benzene $(5.81,1.67$ to 26.44$)$; ionising radiation alone gave an odds ratio of $2 \cdot 35(0.92$ to $6 \cdot 22)$. Raised odds ratios were found for paternal exposure during gestation, but no independent postnatal effect was evident.

Conclusion-These results should be interpreted cautiously because of the small numbers, pverlap with another study, and multiple exposure of some parents. It is important to distinguish periods of parental exposures; identified risk factors were almost exclusively restricted to the time before the child's birth.

Leukaemia Research Fund Centre for Clinical Epidemiology, University of Leeds, Leeds LS2 9NG P A McKinney, PHD, senior research fellow

F E Alexander, PHD, deputy director

R A Cartwright, FFPHM, director

Children's Cancer Unit, University of Newcastle upon Tyne, The Medical School, Newcastle upon Tyne NE2 4HH

L Parker, PHD, lecturer

Correspondence to: Dr Cartwright.

BMf 1991;302:681-7 support this, at least for childhood leukaemia..$^{6011}$ In Gateshead public attention has been directed towards local industrial incinerators.

Parental occupational exposures as risk factors for childhood cancer and leukaemia have been studied by using many different designs, predominantly casecontrol studies. Much of the evidence is conflicting, although this could be explained by the different sources of data, ${ }^{12}$ which include interviews, ${ }^{13}{ }^{14}$ birth certificates, ${ }^{1516}$ and death certificates ${ }^{17}$; consequently the period of exposure is poorly defined. We obtained details on parental employment and exposure for periods before the children's conception, during gestation, and after birth to investigate any possible link with childhood leukaemia.

\section{Subjects and methods}

The three study areas were defined by local authority administrative district boundaries: north Humberside comprised Kingston upon Hull (SAS code $28 \mathrm{KW}$ ), East Yorkshire (28KR), Holderness (28KU), and Beverley $(28 \mathrm{KN})$; Cumbria incorporated Copeland (17FK) and South Lakeland (17FU) and Gateshead was a single district $(06 \mathrm{CH})$. After obtaining the approval of ethics committees, case children were identified from the Yorkshire Regional Children's Tumour Registry (north Humberside) and the Northern Region Children's Malignant Disease Registry (Gateshead and Cumbria). Children in whom leukaemia or non-Hodgkin's lymphoma was diagnosed between 1974 and 1988 while they were resident in one of the areas were eligible for interview. Children born in the same area as that in which the diagnosis was made were eligible for the present analysis.

We planned to obtain two controls for each case matched for sex and date and health district of birth. The controls had to be resident in the same areas at the time their matched case was diagnosed. District health authority birth registers on microfiche were the main source of data. Case children were found on the birth records, and the names and details of eligible children of the same sex were taken. In most instances the date of birth of the control child fell within a few days after that of the case child. Procedures varied slightly among the district health authorities and according to availability of microfiche records; for births before 1970 listings were taken from printed records. The principles of selection were the same irrespective of the data source.

We traced control children through the appropriate family practitioner committees and, if currently registered, approached their parents with the general practitioner's permission. Names of control children no longer registered were submitted to the NHS Central Register for tracing to their current family practitioner committee. Approaches were similarly made through general practitioners, but in a few 
instances these children were discovered to be ineligible because they had moved from the study area before the date that cancer was diagnosed in their matched case. We took the date of diagnosis of the case child as the end of the analysis period for each control.

Not all parents of eligible control children were interviewed, and in these instances another control child was found. Reasons for the parents not being interviewed were recorded. Despite attempts to replace controls because we collected data over a predetermined period some cases did not have two controls.

Face to face home interviews were conducted by seven trained interviewers, who used the same questionnaire for parents of case and control children. Questions concentrated on collecting data relevant to the child's residential history, social history, and parental occupations. One important feature was the identification of the biological (natural) parents of the child and of other adults present in the household during the child's life. We tried to interview both parents, but when only one parent was available surrogate information was accepted.

A complete history of employment and exposure to specific substances and radiation was taken for the biological parents, extending from the time they started work to the end of the analysis period or, if earlier, the time when they stopped seeing their child. Employment and exposure data were collected for any other adults living with the child (including working elder siblings) for more than three months from before birth to the time of diagnosis.

Questions on employment asked for details of both the person's job and the industry in which they were employed. The time was recorded for all occupations, and occupations were coded twice by two independent coders using Office of Population Censuses and Surveys classifications ${ }^{18}$; both sets of codes were entered into a computer and discrepancies resolved in consultation. Office of Population Censuses and Survey codes provide two measures of occupation: industrial class and occupation defined as the type of work an individual performs. The following industrial and occupational groupings were derived from the classification for testing as hypotheses: food industry and food related occupations, chemical industry, farming or agricultural industry and occupations, health related industry and occupations, textile industry and occupations, manufacture of transport equipment industry, metal refining industry and occupations, wood related industry and occupations, and industry and occupations using ores.

All parents and other relevant adults were asked a series of questions on exposure, either at work or through a hobby, to aerosol spray paints, agriculture or farming, benzene, drugs or pharmaceutical industry, exhaust fumes, food industry, furnaces, forge and foundry work, manufacturing transport equipment, metal, petrol or petroleum products, printing or dyeing products, radiation, refining processes, solvents, wood dust. Radiation included ionising and non-ionising sources. In addition, a check list was used for identifying 22 known chemical carcinogens ${ }^{19}$; exposure times of under six months were not coded or computerised. To summarise three separate categories of exposure are encompassed by the data: industry of employment, job or occupation, and specific exposures. An entry for all three categories was made for each adult, although for certain combinations these were correlated-for example, occupation as a joiner would normally but not necessarily be categorised in the timber and wooden furniture industry.

All the data were put into a VAX 8200 series computer; specialised software was used to provide input validation. In order to use $\mathrm{SPSSX}^{20}$ for des- criptive analyses data were transferred to Leeds University's Amdahl computer. SEARCH ${ }^{21}$ and $\mathrm{StatXact}^{22}$ were also used for statistical analyses.

Occupational data were analysed for evidence of risk through six pathways. These were

(1) Biological mother: exposure any time before conception (up to 40 weeks preceding birth)

(2) Biological father: exposure any time before conception (up to 40 weeks preceding birth)

(3) Biological mother: exposure during gestation (the 40 weeks preceding birth)

(4) Biological father: periconceptional and gestational exposure (the 40 weeks preceding birth)

(5) Adult female contact: from birth to time of diagnosis

(6) Adult male contact: from birth to time of diagnosis.

The matched design required that data were available for the case child and at least one control. So that as few of the case children were excluded as possible, the six pathways were analysed separately. For pathways 1 to 4 some occupational data for the relevant biological parent had to be available for the appropriate period. In addition for pathway 4 the biological father must have been living with the family when the child was born. We had intended to collect data on all men in the household during the 40 weeks before the birth, but for practical reasons the date of birth of the child was taken as the start date for adults in the household other than the biological parents. For the child to be included in pathways 5 and 6 answers to the occupational questions were required for one or more adults in contact with the child for at least three months. Housewife was a valid occupation.

After analysis raw data were checked whenever significant results were based on small numbers of exposures $(\leqslant 20)$. For pathway 4 checks on data showed that in every instance the father's exposure covered the time of conception - that is, from 28 to 46 weeks before the birth - so every gestational exposure for fathers included exposures around conception. Exposure was considered dichotomously (exposed or not exposed). The original intention was not to quantify exposure by dose, length of exposure, or (for pathways 5 and 6 ) number of contacts exposed.

For the 25 fathers who reported radiation exposure in the preconceptional and periconceptional and gestational periods a subclassification of their exposure to ionising radiation was produced after checks with the National Registry for Radiation Workers and British Nuclear Fuels, Sellafield, Cumbria. This was not originally envisaged, but was completed to clarify the study findings. Exposures were recorded as certain for those who had had a total external gamma dose according to the national registry or British Nuclear Fuels. Exposures were recorded as possible for other contract workers on nuclear sites and industrial radiographers. This category was chosen after consultation; we acknowledge that these occupations may be in completely registered by the national registry. The unlikely category included people who reported ionising radiation exposures in occupational settings, such as education and medicine. The remainder reported non-ionising radiation exposure and included radar and radio operators.

\section{STATISTICAL METHODS}

All analyses were based on the matched design and produced conditional maximum likelihood estimates of the odds ratios. ${ }^{23}$ Conditional logistic regression was applied for most univariate analyses and for all multivariate analyses. ${ }^{23}$ The score statistic with asymptotic $\chi^{2}$ distribution gave tests of significance, and 95\% confidence intervals based on the asymptotic normal distribution of the regression coefficients are reported. 
As the number of discordant sets available for analysis was often small, all univariate analyses were repeated by using exact estimation of significance and $95 \%$ confidence intervals. ${ }^{24}$ Exact estimates were mid-p corrected to avoid excessively conservative results. Comparison of the results showed little difference between the two methods for those with more than 15 discordant sets, and in the tables the asymptotic method was used unless there were fewer than 15 discordant sets. There was substantial correlation among the exposures. Multivariate analyses were applied to adjust for possible confounding and to test for evidence of independent effects on the same exposure pathway. Small numbers exposed and high correlations were particularly evident for specific chemicals and radiation exposure. Results of adjusted analyses are based on small numbers.

The analyses use all matched sets eligible for each of the six exposure pathways. An additional analysis

TABLE I-Distribution of cases and controls by occupational analysis pathway

\begin{tabular}{|c|c|c|c|c|}
\hline \multirow[b]{2}{*}{ Pathway } & \multicolumn{2}{|c|}{$\begin{array}{l}\text { No of cases } \\
(n=109)\end{array}$} & \multicolumn{2}{|c|}{$\begin{array}{l}\text { No of controls } \\
\quad(n=206)\end{array}$} \\
\hline & Eligible & $\begin{array}{c}\text { Not } \\
\text { eligible }^{\star}\end{array}$ & Eligible & $\begin{array}{c}\text { Not } \\
\text { eligible }^{\star}\end{array}$ \\
\hline \multicolumn{5}{|l|}{ Preconception: } \\
\hline Biological mother & 105 & 4 & 186 & 20 \\
\hline Biological father & 101 & 8 & 178 & 28 \\
\hline \multicolumn{5}{|c|}{ Periconception and gestation: } \\
\hline Biological mother & 105 & 4 & 186 & 20 \\
\hline Biological father & 100 & 9 & 169 & 37 \\
\hline \multicolumn{5}{|l|}{$\begin{array}{l}\text { Postnatal: } \\
\text { Pot }\end{array}$} \\
\hline Women & 109 & 0 & 195 & 11 \\
\hline Men & 109 & 0 & 190 & 16 \\
\hline All pathways & 97 & 12 & 102 & 104 \\
\hline
\end{tabular}

^Includes non-biological parents and parents for whom no occupationa data were available.

TABLE II - Preconceptional exposure and occupation of mothers as risk factors for childhood leukaemia and non-Hodgkin's lymphoma

\begin{tabular}{|c|c|c|c|c|}
\hline \multirow[b]{2}{*}{ Exposure/occupation (OPCS) } & \multicolumn{2}{|c|}{ No $(\%)$ exposed } & \multirow{2}{*}{$\begin{array}{c}\begin{array}{c}\text { No of } \\
\text { discordant } \\
\text { pairs }\end{array} \\
\end{array}$} & \multirow[b]{2}{*}{$\begin{array}{l}\text { Odds ratio ( } 95 \% \\
\text { confidence interval) }\end{array}$} \\
\hline & $\begin{array}{c}\text { Cases } \\
(\mathbf{n}=105)\end{array}$ & $\begin{array}{l}\text { Control } \\
(\mathrm{n}=186)\end{array}$ & & \\
\hline \multicolumn{5}{|l|}{ Industry: } \\
\hline Timber and wooden furniture & $2(2)$ & $4(2)$ & 6 & $0.78(0.10$ to 4.51$)$ \\
\hline \multicolumn{5}{|l|}{ Occupations: } \\
\hline Literary, artistic, and sports & $3(3)$ & $1(0 \cdot 5)$ & 4 & $4.37(0.45$ to 118.32$)$ \\
\hline Catering, cleaning, and hairdressing & $38(36)$ & $37(20)$ & 51 & $2.84(1.56$ to 5.17$)$ \\
\hline Food related ${ }^{\star}$ & $27(26)$ & $25(13)$ & 41 & $2.56(1.32$ to 5.00$)$ \\
\hline Wood related ${ }^{\star}$ & & $5(3)$ & 6 & $0(0$ to $0 \cdot 81)$ \\
\hline \multicolumn{5}{|l|}{ Exposure to: } \\
\hline Carbon tetrachloride & $4(4)$ & $3(2)$ & 6 & $2 \cdot 98(0 \cdot 50$ to $24 \cdot 19)$ \\
\hline Trichloroethene & $2(2)$ & $3(2)$ & 5 & $1 \cdot 16(0.13$ to $7 \cdot 91)$ \\
\hline Xylene & $1(1)$ & & 1 & $x(0.22$ to $x)$ \\
\hline Benzene & $2(2)$ & $1(0 \cdot 5)$ & 3 & $4.00(0.30$ to 117.99$)$ \\
\hline \multicolumn{5}{|l|}{ Coal or graphite } \\
\hline Radiation & $8(8)$ & $14(8)$ & 19 & $1 \cdot 12(0.42$ to 2.90$)$ \\
\hline Wood dust & $9(9)$ & $6(3)$ & 14 & $3.04(1.00$ to $10 \cdot 15)$ \\
\hline
\end{tabular}

^Not standard Office and Population Censuses and Surveys classification. applied to a restricted data set has permitted multivariate methods to search for significant independent effects of the same or related exposures applied on different pathways.

\section{Results}

Cancer was diagnosed in 36 children in Cumbria, 47 in Gateshead, and 68 in north Humberside. The overall distribution of diagnoses was acute lymphoblastic leukaemia (113, 75\%), other leukaemias (21, $14 \%)$, and non-Hodgkin's lymphoma (17, 11\%). Five (13\%) parents of case children were not interviewed in Gateshead, five (11\%) in Cumbria, and nine (13\%) in north Humberside; the main reason was refusal of parents (68\%). Children who were born in the area in which they were diagnosed were eligible for the analysis and comprised $28(78 \%)$ of those interviewed in Cumbria, $41(88 \%)$ in Gateshead, and $54(80 \%)$ in north Humberside.

The intended matching ratio of 1:2 was achieved in north Humberside and Cumbria but in Gateshead it was $1: 1 \cdot 7$. In each area parents of some of the controls were not interviewed (Cumbria $12(17 \%)$, Gateshead $36(38 \%)$, and north Humberside 15 (20\%)); more replacement controls were used in Gateshead. The main reason for not conducting interviews was parental refusal (eight (70\%) Cumbria, 22 (62\%) Gateshead, and $10(65 \%)$ north Humberside).

Table I shows the distribution of cases and controls according to their eligibility for each of the six pathway analyses. Tables II and III give the selected results of the occupational analyses for the same exposure pathways and include results for exposures that were significant $(p<0.05)$ in any one of the six analyses. The odds ratios are not adjusted, but relevant results of multivariate modelling are given in the text.

\section{MOTHERS' EXPOSURES}

Table II shows the significant odds ratios for occupation of biological mothers before conception. The significance of the odds ratio for the catering, cleaning, and hairdressing group remained after adjusting for the food related occupations but the converse was not true. Odds ratios for these two groups remained significant after adjusting for exposure to the food industry and food related jobs. This suggests that an exposure other than food might be involved, but examination of the data did not support this. The only other preconceptional risk for mothers that reached significance was exposure to wood dust.

Only a few mothers were exposed during the gestational period, except for those working in catering, cleaning, and hairdressing. For this group the odds ratio was significant (odds ratio $3 \cdot 12,95 \%$ confidence

TABLE III-Occupation and exposure of fathers as risk factor for childhood leukaemia and non-Hodgkin's lymphoma according to time of exposure

\begin{tabular}{|c|c|c|c|c|c|c|c|c|c|c|c|c|}
\hline \multirow[b]{3}{*}{ Exposure/occupation (OPCS) } & \multicolumn{4}{|c|}{ Preconceptional } & \multicolumn{4}{|c|}{ Periconceptional and gestational } & \multicolumn{4}{|c|}{ Postnatal } \\
\hline & \multicolumn{2}{|c|}{ No (\%) exposed } & \multirow{2}{*}{$\begin{array}{c}\text { No of } \\
\text { discordant } \\
\text { pairs }\end{array}$} & \multirow[b]{2}{*}{$\begin{array}{c}\text { Odds ratio }(95 \% \\
\text { confidence interval) }\end{array}$} & \multicolumn{2}{|c|}{ No (\%) exposed } & \multirow{2}{*}{$\begin{array}{c}\text { No of } \\
\text { discordant } \\
\text { pairs }\end{array}$} & \multirow[b]{2}{*}{$\begin{array}{c}\text { Odds ratio }(95 \% \\
\text { confidence interval) }\end{array}$} & \multicolumn{2}{|c|}{ No $(\%)$ exposed } & \multirow{2}{*}{$\begin{array}{c}\text { No of } \\
\text { discordant } \\
\text { pairs }\end{array}$} & \multirow[b]{2}{*}{$\begin{array}{c}\text { Odds ratio }(95 \% \\
\text { confidence interval) }\end{array}$} \\
\hline & $\begin{array}{c}\text { Cases } \\
(\mathbf{n}=101)\end{array}$ & $\begin{array}{l}\text { Controls } \\
(n=178)\end{array}$ & & & $\begin{array}{c}\text { Cases } \\
(n=100)\end{array}$ & $\begin{array}{l}\text { Controls } \\
(\mathrm{n}=169)\end{array}$ & & & $\begin{array}{c}\text { Cases } \\
(\mathrm{n}=109)\end{array}$ & $\begin{array}{l}\text { Controls } \\
(\mathrm{n}=190)\end{array}$ & & \\
\hline \multicolumn{13}{|l|}{ Industry: } \\
\hline Timber and wooden furniture & $12(12)$ & $9(5)$ & 19 & $2.65(1.02$ to 6.87$)$ & $2(2)$ & $1(1)$ & 3 & $3 \cdot 23(0 \cdot 24$ to $98 \cdot 20)$ & $3(3)$ & $2(1)$ & 5 & $2 \cdot 64(0.39$ to $22 \cdot 50)$ \\
\hline $\begin{array}{l}\text { Occupations: } \\
\text { Literary, artistic, and sports }\end{array}$ & $4(4)$ & & 4 & $x(2.57$ to $x)$ & $3(3)$ & & 3 & $\infty(1.41$ to $x)$ & $4(4)$ & & 4 & $\infty(2 \cdot 22$ to $x)$ \\
\hline Catering, cleaning, and & & & & & & & & & & & & \\
\hline hairdressing & $8(8)$ & $12(7)$ & 18 & $1.17(0.45$ to 3.05$)$ & $4(4)$ & $6(4)$ & 10 & $1.07(0.26$ to 3.99$)$ & $4(4)$ & $10(5)$ & 13 & $0 \cdot 70(0.18$ to $2 \cdot 30)$ \\
\hline Food related $t$ & $8(8)$ & $8(5)$ & 16 & $1.69(0.63$ to 4.54$)$ & $2(2)$ & $2(1)$ & 4 & $1 \cdot 19(0 \cdot 12$ to $11 \cdot 68)$ & $3(3)$ & $4(2)$ & 6 & $1.27(0.21$ to 7.78$)$ \\
\hline Wood related $\dagger$ & $9(9)$ & $5(3)$ & 13 & $3.40(1.04$ to 12.93$)$ & $4(4)$ & $1(1)$ & 5 & $5.46(0.67$ to 138.40$)$ & $5(5)$ & $4(2)$ & 9 & $1.71(0.42$ to 7.31$)$ \\
\hline \multicolumn{13}{|r|}{ (5) } \\
\hline Carbon tetrachloride & $13(13)$ & $8(5)$ & 20 & $2.90(1.14$ to 7.36$)$ & $5(5)$ & $4(2)$ & 9 & $2 \cdot 16(0.54$ to $9 \cdot 14)$ & $6(6)$ & $3(2)$ & 9 & $3.48(0.86$ to 17.22$)$ \\
\hline Trichloroethene & $9(9)$ & $7(4)$ & 16 & $2 \cdot 27(0.84$ to $6 \cdot 16)$ & $7(7)$ & $3(2)$ & 10 & $4.40(1.15$ to 21.01$)$ & $7(6)$ & $5(3)$ & 12 & $2.66(0.82$ to 9.19$)$ \\
\hline Xylene & $5(5)$ & $2(1)$ & 6 & $6.86(0.90$ to 168.29$)$ & $2(2)$ & $1(1)$ & 3 & $3.24(0.24$ to 98.20$)$ & $2(2)$ & $1(1)$ & 3 & $3.24(0.23$ to $98 \cdot 20)$ \\
\hline Benzene & $12(12)$ & $6(3)$ & 13 & $5.81(1.67$ to 26.44$)$ & $4(4)$ & $3(2)$ & 6 & $2.98(0.50$ to 24.19$)$ & $5(5)$ & $7(4)$ & 11 & $1.39(0.38$ to 4.87$)$ \\
\hline Coal or graphite & $8(8)$ & $10(6)$ & 16 & $1.49(0.55$ to 4.09$)$ & $5(5)$ & $4(2)$ & 8 & $2.45(0.54$ to 12.82$)$ & $7(6)$ & $3(2)$ & 9 & $5.07(1.09$ to 36.38$)$ \\
\hline Radiation & $15(15)$ & $10(6)$ & 23 & $3.23(1.36$ to 7.72$)$ & $8(8)$ & $1(1)$ & 9 & $15.06(2.40$ to 337.99$)$ & $9(8)$ & $7(4)$ & 14 & $3.08(1.01$ to 10.33$)$ \\
\hline Wood dust & $33(33)$ & $30(17)$ & 46 & $2 \cdot 73(1.44$ to $5 \cdot 16)$ & $18(18)$ & $20(12)$ & 30 & $1.72(0.57$ to 26.91$)$ & $23(21)$ & $29(15)$ & 43 & $1.49(0.80$ to 2.76$)$ \\
\hline
\end{tabular}

*Jobs are dissimilar.

†Not standard Office of Population Censuses and Surveys classification. 
TABLE IV - Odds ratios (95\% confidence intervals) for exposure of fathers and for working in industries and occupations in which exposure might occur

\begin{tabular}{|c|c|c|c|}
\hline & Preconceptional & Periconceptional and gestational & Postnatal \\
\hline Radiation exposure & $3 \cdot 23(1.36$ to $7 \cdot 72)$ & $15 \cdot 06(2 \cdot 4$ to 337$)$ & $3.08(1.01$ to 10.3$)$ \\
\hline Nuclear industry & $1.00(0.16$ to 6.45$)$ & $1.44(0.13$ to 14.99$)$ & $0.77(0.09$ to 4.62$)$ \\
\hline Health related occupation & $0.59(0.02$ to 9.05$)$ & $0.59(0.02$ to 9.05$)$ & $0.59(0.02$ to 9.05$)$ \\
\hline Coal and graphite exposure & $1.49(0.55$ to 4.09$)$ & $2.45(0.54$ to 12.82$)$ & $5.07(1.09$ to 36.38$)$ \\
\hline Ore related industry & $1.06(0.59$ to 1.93$)$ & $1.34(0.60$ to 2.93$)$ & $1 \cdot 18(0.61$ to 2.25$)$ \\
\hline Ore related occupation & $0.89(0.39$ to 2.05$)$ & $0.63(0.13$ to 2.48$)$ & $1.21(0.48$ to 3.05$)$ \\
\hline Wood dust exposure & $2.73(1.44$ to 5.16$)$ & $1.72(0.83$ to 3.59$)$ & $1.49(0.81$ to 2.76$)$ \\
\hline Timber and wooden furniture & $2.65(1.03$ to 6.87$)$ & $3 \cdot 24(0.24$ to $98 \cdot 2)$ & $2.64(0.39$ to 22.50$)$ \\
\hline Wood related occupation & $3.40(1.04$ to 12.93$)$ & $5.46(0.67$ to 138.4$)$ & $1 \cdot 71(0.42$ to $7 \cdot 31)$ \\
\hline
\end{tabular}

TABLE $\mathrm{V}-$ Exposure of fathers to ionising and non-ionising radiation before children's birth reported at interview

\begin{tabular}{|c|c|c|c|c|}
\hline \multirow[b]{2}{*}{ Time of exposure } & \multicolumn{2}{|c|}{ All areas } & \multicolumn{2}{|c|}{ Gateshead and Humberside } \\
\hline & No of cases & No of controls & No of cases & No of controls \\
\hline \multicolumn{5}{|l|}{ Before conception only: } \\
\hline Certain ionising ${ }^{\star}$ & 2 & $2 \dagger$ & 1 & \\
\hline Possible ionising $\ddagger$ & $2 \dagger$ & $4 \rrbracket$ & 1 & 2 \\
\hline Unlikely ionising & 1 & 3 & 1 & 1 \\
\hline Non-ionising & 2 & & 1 & \\
\hline Total & 7 & 9 & 4 & 3 \\
\hline \multicolumn{5}{|c|}{ Preconception, periconception, and gestation: } \\
\hline Certain ionising ${ }^{\star}$ & $2 \|$ & 1 & & \\
\hline Possible ionising $\ddagger$ & 3 & & 3 & \\
\hline Unlikely ionising & 1 & & & \\
\hline Non-ionising & 2 & & 1 & \\
\hline Total & 8 & 1 & 4 & \\
\hline \multicolumn{5}{|c|}{$\begin{array}{l}\text { ^Exposure confirmed by registration with National Registry for Radiation Workers or British Nuclear Fuels, or } \\
\text { both. }\end{array}$} \\
\hline
\end{tabular}

interval $1 \cdot 12$ to $8 \cdot 65)$. No single occupation accounted for this risk. Analysis of data on women's exposure after the birth showed no significant risks and reflects the overall low frequency of exposure for women at this time.

\section{FATHERS' EXPOSURES}

Preconceptional exposure of biological fathers showed the greatest number of significant odds ratios, although the numbers exposed and length of exposure did not differ from those in the postnatal period (table III). A strong association with wood was shown for the categories investigated: for industrial group, job, and specific exposure. These results reinforce each other and are summarised in table IV. Although the categories are highly correlated, exposure to wood dust remains significant, with only a slightly reduced odds ratio $(2 \cdot 4)$ after adjusting for the industry and occupation categories. Adjusting for painting as an occupation and solvent and chemical exposures, for which wood dust might be a proxy, did not further reduce the risk.

Fathers were asked, "either at work or as a hobby have you ever been exposed to radiation?" Exposures contributing to all analyses were in an occupational setting. The threefold risk associated with radiation exposure during the preconceptional period (table III) remained significant after adjusting for possible confounding factors (health related occupations, employment in the energy supply industry, chemicals quoted in table III). Confining analysis to reported exposure to ionising radiation gave an odds ratio of $2 \cdot 35(0.92$ to $6 \cdot 22)$ for preconceptional exposure.

The only independent contributions to risk in the preconceptional period were exposure to wood dust (odds ratio $3.00,1.50$ to 5.90 ), radiation $(2.94,1 \cdot 13$ to 7.63$)$, and benzene $(4.82,1.24$ to 18.84$)$. The significant odds ratios for carbon tetrachloride and xylene exposure were not independent of the observations for wood, benzene, and radiation.

In the periconceptional gestational period several odds ratios were raised, but only those for exposure to radiation and trichloroethene were significant and for radiation the $95 \%$ confidence intervals were wide (table III). For reported exposure to only ionising radiation the odds ratio was $12(1 \cdot 77$ to $277 \cdot y 6)$. The odds ratio for radiation exposure was reduced to 12.57 $(1.49$ to $106 \cdot 38)$ after adjusting for the possible confounding between radiation and chemicals. The risk associated with trichloroethene was not significant. Cases contributing to the radiation exposure were distributed among the three study areas. For adult males living in the household after birth exposure to coal or graphite was associated with a fivefold increased risk and radiation with a threefold increased risk (table III).

Table IV summarises the exposures of fathers and other men in contact with the children grouping together selected industries and jobs to place significant odds ratios in context. The increased risk associated with exposure to radiation does not seem to be linked to working in either the nuclear industry or in a medical setting. Similarly the risk associated with coal or graphite exposure after the birth was not reflected in the ore related groupings. Specific chemical exposures were unrelated to working in the chemical industry for the odds ratios were $1.11(0.46$ to 2.71$)$ before conception, $0.91(0 \cdot 17$ to $4 \cdot 11)$ around conception and gestation, and $1.36(0.39$ to 4.65$)$ after birth.

\section{COMPARATIVE ANALYSIS OF EXPOSURE PATHWAYS}

To determine whether risks were concentrated within particular exposure pathways, multivariate analyses were applied to a restricted data set (table I) Fathers' exposure to wood dust emerged as a risk factor specific to the preconceptional period $(2.75,1.16$ to 6.53). A similar effect was evident for mothers' exposure before conception $(9.00,0.92$ to 88.40 adjusted for fathers' and mothers' exposures in the other pathways).

Data for chemical and radiation exposure were based on such small numbers and so highly correlated that the three pathways could not always be distinguished. No evidence was found, however, of risk associated with radiation exposure after birth alone $(0 \cdot 82,0 \cdot 14$ to 4.94 after adjusting for preconceptional and periconceptional exposure). Exposure before or around conception, or both, was significant after adjusting for postnatal exposure. The data cannot distinguish between the risk of exposure before and after conception (before conception $1.59,0.55$ to 4.60 ; periconception and gestation $10.75,0.64$ to 179.78 in the adjusted analysis; score test for the two: $\chi^{2}=6.90$, $\mathrm{df}=2, \mathrm{p}<0.05)$. Further examination of the data suggested that the periconceptional and gestational period was critical (table V). There was little difference between the proportions of case and control children whose fathers reported exposure to ionising radiation only in the preconceptional period, although more fathers of case children were exposed in the periconceptional and gestational period for each category of exposure.

The effects of benzene exposure seem to be mainly 
preconceptional, and the risks associated with radiation and benzene were independent of each other. The risk for fathers' exposure to coal and graphite, most prominent in the postnatal period, is substantially reduced and loses significance after adjusting for benzene and radiation exposures during the other relevant times.

\section{Discussion}

The diagnostic distribution and proportion of case children whose parents were interviewed was similar in each area, although more parents of control children in Gateshead were not interviewed compared with the proportion in the other areas. In addition, a higher proportion of children whose condition was diagnosed in Gateshead were born there and eligible for inclusion in this analysis. Both these differences could be accounted for by the socioeconomic differences between Gateshead (predominantly lower status) and west Cumbria and north Humberside (higher status). The matched case-control design should eliminate any potential bias caused by demographic differences among areas.

Previous investigations of childhood cancer and parental occupation have found various associations with particular risk factors. Our study, with its highly specific exposure pathways, failed to support other work that has suggested increased risk with parental exposure to pesticides, ${ }^{1425-27}$ plastics, ${ }^{1425}$ or paints and pigments. ${ }^{13} 14252728$

Certain occupations of parents have also been associated with childhood leukaemia, but we found no association with the chemical industry ${ }^{81325}$ farming and agriculture, ${ }^{82527}$ the textile industry, ${ }^{13}$ medical and social services, ${ }^{132527}$ painting (including spray paints), ${ }^{1425} 28$ metal refining, ${ }^{1425}$ manufacturing transport equipment and machinery. ${ }^{1427-29}$ The lack of an association may reflect the low level of employment in certain of these industries in the areas studied. An important difficulty in comparing results of studies is the diversity in definitions of exposure, and this is particularly pertinent to occupational histories. Various coding schemes are applied to employment histories, and exposure to substances may be derived from matrices inferred by job title, gathered specifically. Therefore interpretations in the context of other research must be cautious.

\section{VALIDITY OF FINDINGS}

Our results are based only on data obtained by home interview, and reported exposures in the workplace or home were not validated, except for positive reports of exposure to radiation. In addition exposure was not quantified, which precludes the calculation of dose response. For all these reasons our findings must be interpreted as epidemiological associations, which may or may not agree with other independent observations, but cannot be considered to show a direct causal link. In addition 480 comparisons were computed in the analysis and some significant associations might have been expected purely by chance. Four results were significantly negative.

All case-control studies are subject to bias, and although our study was designed to avoid many of the pitfalls, some biases may remain. Interviewer bias was minimised by training of interviewers, who interviewed parents using a highly structured questionnaire. Potential bias in ascertaining case children will be minimal as they were listed from specialised local children's cancer registries.

Differential recall of information between case and control parents can always be cited as an explanation for significant positive results. Parents of children with leukaemia might be expected to overreport exposures, especially to the known leukaemogens benzene and radiation. Certain features of the current results, however, suggest that recall bias is unlikely. If recall bias were strongly influencing the interview responses a similar number of excesses might be expected for both mothers and fathers and across the three periods of exposure. This is not the case in either instance and suggests that recall bias is not operating strongly in our data set. The results for fathers' exposures during the preconceptional period cannot be explained by recall bias resulting from publicity after publication of work by Gardner $e t a l^{89}$ as all interviewing was completed before the paper's publication. Some of the case parents, however, had been interviewed or filled in questionnaires for previous studies. ${ }^{9031}$ The length of time between the collection of previous data and our study was considered to be sufficiently large not to influence the responses in the present study. In addition the occupational section formed a small part of previous data collection exercises.

\section{PRECONCEPTIONAL EXPOSURES}

For mothers and fathers exposed in the preconceptional period the fetus and child are proposed to be put at risk through alterations in the germ cells or the gonads. ${ }^{89}$ Our results show some associations for mothers working in food related occupations or in catering, cleaning, hairdressing, and other personal services before conception. There was no evidence that the food occupational category defined for this study had a stronger association than the more heterogeneous classification used by the Office of Population Censuses and Surveys. A previous study has shown weak associations between maternal exposure (during gestation) to the food industry and all childhood cancer. ${ }^{27}$ The absence of any specific range of occupations accounting for the significantly raised risk suggests that our finding may be due to chance.

Fathers working in the timber and wooden furniture industry, working in wood related occupations, and having exposure to wood dust before conception all showed a significant association with childhood leukaemia. The odds ratios of these variables during the periconceptional and gestational or postnatal periods were not significant. Multivariate modelling indicated that exposure to wood dust was the strongest link and in terms of a biological effect would support the conclusion that these results may represent a real association. No previous reports of this highly specific link seem to exist, although much previous research did not examine exposures defined in this manner. ${ }^{32}$ Of interest is the significant odds ratio for exposure of mothers to wood dust before conception; wood dust was the only significant risk exposure that was common to mothers and fathers for the same period. A casecontrol study of children with acute myeloblastic leukaemia found increased risk for the children of mothers exposed to sawdust during pregnancy, although numbers were small. ${ }^{14}$

Exposure of fathers before conception to carbon tetrachloride and benzene was associated with an increased risk, and whilst exposure to trichloroethene conveyed a risk in the gestational and periconceptional period. Employment in the chemical industry was not a risk factor, which is not surprising given the diversity of the exposures. Childhood leukaemia has been linked to fathers' exposure to solvents before conception and during gestation ${ }^{14}$ and postnatally ${ }^{28}$; other observations have linked mothers' solvent exposure to their children's disease. ${ }^{1325}$ Our study does not support the association, although the number of mothers reporting exposure to solvents was extremely small.

Benzene is contained in petrol and petrol exhaust emissions,,$^{33}$ and some studies have suggested that paternal exposure to exhaust fumes or petrol, or both, 
might be linked to childhood leukaemia. ${ }^{1+273435}$ Our results do not substantiate this in terms of occupations, but if benzene, a known leukaemogen, ${ }^{36}$ is the underlying risk factor individual occupations (or groups) might mask the effect of benzene exposure as benzene has been used in the industry only since the 1960s, with protective clothing and careful monitoring of exposures. Individuals claiming exposure are unlikely to have received a large dose. One study failed to find any risk associated with fathers' exposure to benzene. ${ }^{3}$

\section{EXPOSURE TO RADIATION}

Direct exposure to ionising radiation is known to cause leukaemia in certain circumstances. Previous epidemiological studies have suggested that preconceptional exposure of fathers to ionising radiation through occupation ${ }^{8}$ or medical radiography ${ }^{2538}$ may increase the risk of their children developing leukaemia. This is thought to be caused by germ cell mutation, although there is considerable debate regarding the biological mechanisms entailed. ${ }^{39} 40$ Other research has failed to link occupational exposure to ionising radiation in the equivalent time period. ${ }^{14} 29$ Our results on radiation exposure are of limited value by themselves, but make an important contribution to recent work. The study design was such that the formal analyses reported on all levels of radiation exposure recorded at interview. The later subclassification into certain, possible, and unlikely exposure was a logical extension to aid interpretation. Our results offer support for the hypothesis that parental exposure to radiation has an effect prenatally (pathways 1 to 4 ). The increased odds ratio for fathers across the three periods analysed were highly correlated; there was no evidence of independent risk from postnatal exposure. Exposure of parents before their child's birth makes a significant contribution to the risk, and although the data are sparse and ambiguous, this risk seems greatest in the 40 weeks before birth, which includes the time of conception. Further examination by using additional data on individual exposure histories is consistent with this. This risk is not confined to Cumbria (see table V), and exposed case fathers did not work exclusively in the nuclear industry. Most of the remainder reported working as industrial radiographers. Of the eight case children whose fathers were exposed around the time of conception or during gestation, seven were diagnosed as having acute lymphoblastic leukaemia $(87.5 \%) ; 75 \%$ of the case children in the series had acute lymphoblastic leukaemia.

Our findings are not independent of those of Gardner $e t a l^{8}$ because of the geographical overlap and similarity of methods of selecting controls. Fathers exposed to radiation prenatally in the current study were checked against the database of Gardner et al. Four matches were found: one control, one nonnuclear industrial worker, and two Seascale residents who were employed in the nuclear industry. The non-nuclear worker was considered as unexposed to ionising radiation by Gardner et al. ${ }^{8}$ The raised odds ratio for confirmed paternal exposure to radiation in the periconceptional and gestational period is entirely dependent on cases included in the study by Gardner et al.

Overall, interpretation of our results is limited by the nature of epidemiological research. Our findings show primarily that the period before and around the time of conception is particularly relevant for fathers' exposure. Benzene and wood dust exposures were identified as risk factors in addition to ionising radiation. Further analyses in respect of occupational radiation exposure are being considered.

The Leukaemia Research Fund supports the Clinical Epidemiology Centre at Leeds University. We wish to thank the following medical collaborators on the study: Drs C C Bailey, I Lewis (Leeds), I Beddis, A V Sheard, J M Dunlop (Hull), A W Craft, J Kernahan (Newcastle), D F Henley (Gateshead), J Platt, M B R Roberts, J Terrell, J Munro, M Jepson, $\mathrm{N}$ West (Cumbria), P Morris-Jones, and R Stevens (Manchester). We thank P Roberts, J O'Sullivan (Leeds), B Routledge, A Ulyett, C Wilson (Cumbria), D Fadden, M Moore (Gateshead) for conducting interviews; J Hargreaves for administration, development, and support work; B Pearlman for interviewer training; Y Gibbon and S Fitzpatrick for coding; staff of the family practitioner committees and district health authority who facilitated our work; J Williams, J Carrette, and D Rowland for computing; and A Pickles and A McKeating for typing the manuscript. We thank H Lilley and the Yorkshire Children's Tumour Registry, supported by the Leeds Candlelighters, for continued assistance and acknowledge the collaboration of L More from the Northern Children's Malignant Disease Registry.

1 Craft AW, Birch JM. Childhood cancer in Cumbria. Lancet 1983;ii: 1299. 2 Black D. Investigation of the possible increased incidence of cancer in West Cumbria. Report of Independent Advisory Group. London: HMSO, 1984.

3 Gardner MJ, Hall AJ, Downes S, Terrell JD. Follow-up study of children born to mothers resident in Seascale, West Cumbria (Birth Cohort). BMf to mothers residen

4 McKinney PA, Alexander FE, Cartwright RA, Ricketts TJ. The Leukaemia Research Fund data collection survey: descriptive epidemiology of acute lymphoblastic leukaemia. Leukaemia 1989;3:880-5.

5 Cartwright RA, Alexander FE, McKinney PA, Ricketts TJ, Hayhoe FJG, Clayton DGC. Leukaemia and lymphoma. An atlas of distribution within areas of England and Wales 1984-1988. London: Leukaemia Research Fund, 1990.

6 Alexander FE, McKinney PA, Cartwright RA, Ricketts TJ. Investigation of spatial clustering of rare diseases: childhood malignancies in Nort Humberside. I Epidemiol Community Health 1990;44:39-46.

7 Openshaw S, Craft AW, Charlton M, Birch JM. Investigation of leukaemi clusters by use of a geographical analysis machine. Lancet 1988;i:272-3

8 Gardner MJ, Snee MP, Hall AJ, Powell CA, Downes S, Terrell JD. Results of case-control study of leukaemia and lymphoma among young people near Sellafield nuclear plant in West Cumbria. BMJ 1990;300:423-9.

9 Gardner MJ, Hall AJ, Snee MP, Downes S, Powell CA, Terrell JD. Methods and basic data of case-control study of leukaemia and lymphoma among young people near Sellafield nuclear plant in West Cumbria. $B M$ 1990;300:429-34.

10 Alexander FE, McKinney PA, Cartwright RA. The pattern of childhood and related adult malignancies near Kingston-upon-Hull (in press).

11 Baxter MS, East BW, MacKenzie AB, Scott EM. A review of radioactivity in and around the Capper Pass smelter, Melton Works, north Humberside. Scottish and around the Capper Pass smelter, Melton Works, north Humberside. Scottish Universtites Research and Reactor
Health Authority, February 1990.

12 Arundel SE, Kinnier-Wilson LM. Parental occupations and cancer: a review of the literature. $\mathcal{F}$ Epidemiol Community Health 1986;40:30-6.

13 Van Steensel-Moll HA, Valkenburg HA, van Zanen GE. Childhood leukemia and parental occupation. Am f Epidemiol 1985;121:214-6.

14 Buckley JD, Robison LL, Swotinsky R, et al. Occupational exposures of parents of children with acute non-lymphocytic leukemia: a report from the children's cancer study group. Cancer Res 1989;49:4030-7.

15 Fabia J, Thuy TD. Occupation of father at time of birth of children dying of malignant diseases. British fournal of Preventive and Social Medicin 1974;28:98-100

$16 \mathrm{Kwa}$ S-L, Fine LJ. The association between parental occupation and childhood malignancy. F Occup Med 1980;22:792-4.

17 Sanders BM, White GC, Draper GJ. Occupations of fathers of children dying from neoplasms. F Epidemiol Community Health 1981;35:245-50.

18 Office of Population Censuses and Surveys. Classification of occupations 1980. London: HMSO, 1980

19 International Association for Research on Cancer. Monograph on the evaluation of carcinogenic risk to humans. Overall evaluation of carcinogenicity: update of IARC monograph vol $1-42$ supplement 7 . Lyons: IARC, 1987.

IARC monograph vol l-42 supplement 7. Lyons: IARC, 1987.
20 SPSS Inc. SPSSX Users' guide. Chicago: McGraw-Hill. 1983.

21 MacFarlane GJ, Boyle P, Maisoneuve P. SEARCH: a computer package for the analysis of case-control studies. Lyons: International Association for Research analysis of case-contr.
on Cancer, 1988 .

22 Melita CR. Stat Xact. Caambridge, Massachusetts: Cvtel Software Corporation, 1990

23 Breslow NE, Day NE. Indirect standardization and the multiplicative mode for rates with reference to the age adjustment of cancer incidence and relative frequency data. $\mathcal{F}$ Chronic Dis 1975;28:289-303.

24 Melita CR, Patel NR, Gray R. On computing an exact confidence interval for the common odds ratio in several $2 \times 2$ contingency tables. Journal of th American Statistics Association 1985;80:969-73.

25 Shu XO, Gao YT, Brinton LA, et al. A population-based case-control study of childhood leukemia in Shanghai. Cancer 1988;62:635-44

26 Reeves JD, Driggers DA, Killey VA. Household insecticide associated aplastic anaemia and acute leukaemia in children. Lancet 1981;ii:300-1.

27 Hemminki K, Saloniemi I, Salonen T, Partanen T, Vainio H. Childhood cancer and parental occupation in Finland. I Epidemiol Community Healt 1981;35:11-5.

28 Lowengart RA, Peters JM, Cicioni C, et al. Childhood leukemia and parents' occupational and home exposures. F Natl Cancer Inst 1987;79:39-46.

29 Hicks N, Zack M, Caldwell GG, Ferubach DJ, Falletta JM. Childhood cancer and occupational radiation exposure in parents. Cancer 1984;53:1637-43.

30 Stewart A, Webb J, Hewitt D. OSCC: A survey of childhood malignancies. BM7 1958;: : 1495-508.

31 McKinney PA, Cartwright RA, Saiu JMT, et al. The inter-regional epidemiological study of childhood cancer (IRESCC): a case control study of logical study of childhood cancer (IRESCC): a case control study of
aetiological factors in leukaemia and lymphoma. Arch Dis Child 1987;62: aetiological

32 Savitz DM, Chen J. Parental occupation and childhood cancer: review of epidemiological studies. Environ Health Perspect 1990;88:325-7. 
33 Infante PF, Schwartz E, Cahill R. Benzene in petrol: a continuing hazard. Lancet 1990;336:814-

34 Vianna NJ, Kovasznay B, Polan A, Ju C. Infant leukemia and paterna exposure to motor vehicle exhaust fumes. F Occup Med 1984;26:679-82.

35 Gold EB, Diener MD, Szklo M. Parental occupations and cancer in children.

A case control study and review of the methodologic issues. $\mathcal{F}$ Occup Med 1982;24:578-84

6ronkite EP, Drew RT, Inoue T, Bullis JE. Benzene hematotoxicity and leukemogenesis. Am f Ind Med 1985;7:447-56.

37 Shaw G, Lavey R, Jackson R, Austin D. Association of childhood leukemia with maternal age, birth order and paternal occupation. Am f Epidemiol 1984;119:788-95.

38 Graham S, Levin ML, Lilienfeld AM, et al. Preconception, intrauterine and postnatal irradiation as related to leukemia. $\mathcal{F}$ Natl Cancer Inst 1966;19. 347-71.

.

40 Peto J. Radon and the risks of cancer. Nature 1990;345:389-90.

\title{
Case-control study of leukaemia and non-Hodgkin's lymphoma in children in Caithness near the Dounreay nuclear installation
}

\author{
James D Urquhart, Roger J Black, Michael J Muirhead, Linda Sharp, Margaret Maxwell, \\ O B Eden, David Adams Jones
}

Information and Statistics Division, Scottish Health Service, Common Services Agency, Edinburgh EH5 3SQ

James D Urquhart, MSC, senior principal research officer Roger J Black, MA, senior research officer

Michael J Muirhead, MA, statistician

Linda Sharp, BSC, statistician Margaret Maxwell, MA, research officer

David Adams Jones, statistician

Department of Paediatric Haematology, Royal Hospital for Sick Children, Edinburgh EH9 1LF O B Eden, FRCPED, consultant haematologist

Correspondence to: Mr Urquhart.

$B M \mathcal{F} 1991 ; 302: 687-92$

\section{Abstract}

Objective-To examine whether the observed excess of childhood leukaemia and non-Hodgkin's lymphoma in the area around the Dounreay nuclear installation is associated with established risk factors, or with factors related to the plant, or with parental occupation in the nuclear industry.

Design-Case-control study.

Setting-Caithness local government district.

Subjects - 14 cases of leukaemia and non-Hodgkin's lymphoma occurring in children aged under 15 years diagnosed in the area between 1970 and 1986 and 55 controls matched for sex, date of birth, and area of residence within Caithness at time of birth.

Main outcome measures-Antenatal abdominal $x$ ray examination; drugs taken and viral infections during pregnancy; father's occupation; father's employment at Dounreay and radiation dose; distance of usual residence from the path of microwave beams, preconceptional exposure to non-ionising radiation in the father; and other lifestyle factors.

Results - No raised relative risks were found for prenatal exposure to $x$ rays, social class of parents, employment at Dounreay before conception or diagnosis, father's dose of ionising radiation before conception, or child's residence within $50 \mathrm{~m}$ of the path of microwave transmission beams. Results also proved negative for all lifestyle factors except an apparent association with use of beaches within 25 $\mathrm{km}$ of Dounreay. However, this result was based on small numbers, arose in the context of multiple hypothesis testing, and is certainly vulnerable to possible systematic bias.

Conclusion-The raised incidence of childhood leukaemia and non-Hodgkin's lymphoma around Dounreay cannot be explained by paternal occupation at Dounreay or by paternal exposure to external ionising radiation before conception. The observation of an apparent association between the use of beaches around Dounreay and the development of childhood leukaemia and non-Hodgkin's lymphoma might be an artefact of multiple testing and influenced by recall bias.

\section{Introduction}

In 1988 the Committee on the Medical Aspects of Radiation in the Environment (COMARE) published the report of its investigation into the incidence of leukaemia and non-Hodgkin's lymphoma in young people in the area around the Dounreay nuclear installation in Caithness during 1968-84. ${ }^{\prime}$ The committee concluded that the apparent excess incidence within the area $25 \mathrm{~km}$ from the plant during 1979-84 justified further study. The case-control study of all cases of leukaemia and non-Hodgkin's lymphoma occurring in children aged under 15 in Caithness during 1968-86 reported in this paper forms one part of the series of investigations recommended by the committee. A follow up study of incidence of cancer in birth and school cohorts in the Dounreay area will be reported later.

Because of the small number of cases the study was not expected to provide insights into the general aetiology of childhood leukaemia; the primary objective was to determine the extent to which the excess incidence of leukaemia and non-Hodgkin's lymphoma occurring within $25 \mathrm{~km}$ of the plant might be explained by risk factors suggested by earlier studies. These factors include maternal exposure to $x$ rays during pregnancy $^{2}$ and aspects of parental occupation, including paternal exposure to relatively small doses of ionising radiation before conception of the child. Other risk factors examined, such as patterns of viral infection in the mother and certain aspects of lifestyle, are necessarily somewhat speculative.

Although the main emphasis of the study was to use case-control methods to investigate cases of leukaemia and non-Hodgkin's lymphoma occurring within $25 \mathrm{~km}$ of Dounreay, it was recognised that possible risk factors relating to employment in particular would be present among people living in a wider area of Caithness. For this reason the study was extended to include all cases of childhood leukaemia and nonHodgkin's lymphoma occurring within Caithness from 1968 to 1986 . Results are presented separately for the $25 \mathrm{~km}$ zone and for the whole of Caithness.

\section{Subjects and methods}

All registered cases of leukaemia and non-Hodgkin's lymphoma in chidren resident in Caithness during 1968-86 were included in the study, and we selected controls who were matched with case children for sex and date of birth. The controls were also matched by mother's area of residence at birth, and for this purpose Caithness was divided into two zones: $(a)$ the area lying within $25 \mathrm{~km}$ of the Dounreay nuclear installation and (b) the remainder of Caithness. For each case the birth register was used to select four controls for whom the mother's zone of residence at birth corresponded with that of the case child. The controls selected were those meeting the matching criteria with dates of birth closest to the dates of birth of the index cases.

Two cases in children who were resident within 25 $\mathrm{km}$ of the Dounreay nuclear installation at the time of diagnosis were born outwith Caithness. To permit analysis of risk factors relating to the period before birth four controls were selected for these two cases from the registration districts of birth. An additional four matched controls with mothers who were resident in the inner $25 \mathrm{~km}$ zone at the time of birth were also 